\title{
Research on the Quality of Life of the Parents by Functions, Activities, Participation, and Environmental Factors of Children with Cerebral Palsy Using ICF-CY Checklist
}

\author{
Hyun Sook Kwon, Sung Min Son \\ Department of Physical Therapy, Graduate School of Health Sciences, Cheongju University, Cheongju, Korea
}

\begin{abstract}
Purpose: This study examined whether the quality of life of parents of children with cerebral palsy is affected by the functions, activities, participation, and environmental factors using an ICF-CY check list.

Methods: This study recruited in 26 parents of children with cerebral palsy. The functions, activities, participation, and environmental factors of the children were evaluated using ICF-CY checklist. To measure the quality of life of parents, this study used world health organization quality of life (WHOOOL-BREF), which was composed of a total of 26 questions. The GMFCS (gross motor function classification system) was used to assess the degree of disability in the children. Multiple regression analysis was performed to examine the effects of the ICF-CY checklist on the quality of life. Correlation analysis was performed to examine the correlation between GMFCS and WHOQOL.

Results: The functions, activities, participation, and environmental factors were significantly different from WHOQOL-BREF. On the other hand, the contextual factor showed a significant difference in the neuromusculoskeletal and movement-related functions (b7), and service, systems, and policies (e5) $(\mathrm{p}<0.05)$.

Conclusion: This study suggests that the functions and environmental factors affect the quality of life of parents of children with cerebral palsy. Therefore, these findings suggest that contextual factors, such as neuromusculoskeletal and movement-related functions (b7), and service, systems and policies (e5), which can be facilitators, should be considered for improving the quality of life of parents of children with cerebral palsy.
\end{abstract}

Keywords: ICF-CY checklist, Cerebral palsy, Quality of life

\section{서 론}

뇌성마비는 발달 중에 있는 태아 또는 아동의 뇌에 발생한 비진행성 병변으로 운동장애와 경직으로 인해 움직임과 자세조절, 감각, 인지, 의사표현 장애 등이 동반될 수 있으며, ${ }^{1}$ 이로 인해 뇌성마비 아동들 은 정상적인 발달을 경험하지 못하게 된다. ${ }^{2}$ 뇌성마비 아동은 신체기 능에 따라 일상생활 참여도가 매우 다양하게 나타나고, ${ }^{3}$ 신체기능 정 도에 따라 일상생활활동과 사회참여에서도 제한이 나타난다. 과거의 뇌성마비 아동의 치료 목적은 신체기능 수준의 향상을 우선 순위로 설정하였다. 하지만, 아동이 사회적 역할을 수행하기 위해서는 구조 나 기능뿐만 아니라 활동과 참여, 환경요인 등을 고려하여 종합적으 로 목표를 설정해야 할 필요가 있다. ${ }^{4}$ 이러한 부분들을 고려하기 위해 world health organization (WHO)에서는 ICF를 사용하여 뇌성마비 아

\section{동의 평가에 적용하였다. ${ }^{5}$}

international classification of functioning (ICF, disability, and health) 는 신체 기능, 구조, 활동과 참여, 환경요인을 약 1,400 개의 항목으로 구성하였으며, 체계적이고 표준화된 방법으로 개인의 기능 수준을 분류하고 있다. ${ }^{6}$ 아동의 건강상태는 어른들과 다르기에 아동의 발달 에 영향을 줄수 있는 교육, 건강 및 사회 생활 측정을 위해 ICF에서부 터 분리되어 ICF-CY가 개발되었다. 아동의 기능 수준은 활동과 참 여 뿐만 아니라 삶의 질 수준에 중요한 영향을 미치며, ${ }^{8}$ 삶의 질에 대 한 평가는 중요한 영역으로 인식되고 있다.9

$\mathrm{Lee}$ 와 $\mathrm{Ko}^{10}$ 의 연구에서 뇌성마비 아동의 기능과 활동참여가 높을 수록 삶의 질이 향상되며, 보호자의 관리 수준이 뇌성마비 아동의 삶 의 질에 영향을 미치는 것으로 알려져 있다. 하지만, 장애 아동의 보 호자는 많은 시간을 돌봄과 치료에 소비하고 있어 생산적인 일이나 
가사에 참여하지 못하고 있으며, 아동의 교육이나 치료로 인한 지출 로 재정적인 어려움을 겪을 수 있다.1 아동의 기능적 활동이 스스로 이동을 하지 못하여 보호자에 대한 의존도가 높아지면, 이로 인해 뇌 성마비 아동의 보호자는 삶의 질에 저하, 부정적 정서, 스트레스와 재 정적 부담 및 대인관계에서 문제가 발생할 수 있다고 보고되었다. ${ }^{12}$ 이 와 같이 보호자에게 나타나는 심리적 변화는 뇌성마비 아동에게 불 안감을 줄 수 있으며, 이로 인해 아동의 성장과 심리적인 부분에서 부 정적인 영향을 줄 수 있다. 따라서 보호자의 긍정적인 태도는 아동의 기능과 심리상태에 긍정적인 영향을 미치고 있음을 알 수 있다.13

많은 선행 연구에서 아동의 기능 수준이 삶의 질에 영향을 미칠 수 있는 것으로 중요하게 고려되었다. ${ }^{8,10,15}$ 또한, 삶의 질을 평가하는 것은 기능적인 부분을 평가하는 것보다 뇌성마비 아동이 학교에서 의 정서적, 사회적 적응 행동을 예측하는 데 도움이 된다고 하였다. ${ }^{4}$ 그래서, 선행연구들은 뇌성마비 아동의 삶의 질이나 보호자의 삶의 질이 아동의 기능 수준, 신체 활동과 관련된 부분들을 연구하였다. ${ }^{15}$ 선행연구에서는 아동의 기능 수준에 따른 뇌성마비 아동과 부모의 삶의 질에 대한 수준을 파악하는 연구가 대부분이었으며, ${ }^{16}$ 뇌성마비 아동의 기능, 활동과 참여, 환경 등 세부적인 요소가 보호자의 삶의 질에 어떠한 영향을 미치는지에 대한 연구가 부족한 실정이다. 따라 서 본 연구에서는 ICF-CY 체크리스트를 활용하여 뇌성마비 아동의 기능, 활동과 참여, 환경의 요소가 보호자의 삶의 질에 어떠한 영향 을 주는지 알아보고, 나아가 뇌성마비 아동을 치료하는 데 있어 치료 목표를 제공해주고자 한다.

\section{방 법}

\section{1. 연구 대상자}

본 연구는 자기공명영상(magnetic resonance imaging, MRI) 혹은 전산 단층화검사(computed tomography, CT)상에 뇌성마비로 진단을 받은
아동의 보호자 26 명을 대상으로 하였다. 보호자에게 본 연구의 목적 을 서면으로 설명하였으며, 선정기준은 본 연구의 목적을 이해하고, 동의한 보호자를 대상으로 하였다. 본 연구에서 제외 기준은 6 개월 이내에 보톡스 주사를 투여한 아동, 뇌성마비 외 다른 질환이 있는 아동, 정형외과적 수술을 한 아동의 보호자는 연구 대상에서 제외되 었다. 대상자의 일반적인 특성은 Table 1과 같다.

\section{2. 평가도구 및 방법}

1) ICF-CY Checklist (international classification of functioning, disability and health: children \& youth version checklist) 본 연구에는 7-12세를 대상으로 사용하는 한글화된 ICF-CY 체크리 스트를 보호자와 치료사가 함께 설문에 참여하였다. ICF-CY 체크리 스트는 기능영역, 활동과 참여영역, 환경 영역으로 나누어진다. 기능 영역은 총 8 개의 영역(정신기능, 감각기능과 통증, 음성 및 말하기 기 능, 심혈관계, 혈액학적, 면역학적, 호흡기계의 기능, 소화기계, 대사 및 내분비계 기능, 비뇨생식기와 생식기능, 신경근육골격 및 운동과 연 관된 기능, 피부와 관련 구조의 기능)으로 구성되어 있다..$^{7}$ 각 문항의 응답은 이상없음(0점), 경도 이상(1점), 중도 이상(2점), 고도 이상(3 점), 완전 이상(4점)으로 분류된다. ${ }^{17}$ 활동과 참여영역은 총 9 개의 영역 (학습과 지식 적용, 일반적인 임무와 요구, 의사소통, 이동, 자기관리, 가정생활, 대인관계, 주요 생활영역, 공동체 생활, 사회생활 및 시민으 로서의 생활)으로 구성되어 있다. ${ }^{18}$ 각 문항의 응답은 어려움 없음 $(0$ 점), 경도의 어려움(1점), 중도의 어려움(2점), 고도의 어려움(3점), 완 전한 어려움(4점)으로 분류된다. ${ }^{17}$ 환경영역은총 5 개의 영역(제품과 기술, 자연적인 환경과 인위적인 환경의 변화, 지원 그리고 관계, 태도, 서비스, 시스템 그리고 정책)으로 구성되어 있다. ${ }^{17}$ 각 문항의 응답은 장애 요인 없음(0점), 경도의 장애(1점), 중도의 장애(2점), 고도의 장애 (3점), 완전한 장애(4점)으로 분류된다. ${ }^{17}$ 각 영역의 항목들은 5 점 척도 로 평가된다. 각 영역의 점수를 합한 후 평균값을 내 분석하였다. ICF-

Table 1. General characteristics of children with cerebral palsy and their parents.

$(N=26)$

\begin{tabular}{|c|c|c|}
\hline \multirow[t]{7}{*}{ Children with Cerebral palsy } & Age & $9.69 \pm 0.39$ \\
\hline & Gender (Male/Female) & $11(42.3) / 15(57.7)$ \\
\hline & Delivery mode (NSVD/C-sec) & $12(46.2) / 14(53.8)$ \\
\hline & Gestational period & $34.38 \pm 0.78$ \\
\hline & Birth weight & $2.58 \pm 0.09$ \\
\hline & Education type (normal school / special school / the other) & $17(65.4) / 8(30.8) / 1(3.8)$ \\
\hline & Types of cerebral palsy (spastic/Athetoid/Hypotonia) & $23(88.5) / 2(7.7) / 1(3.8)$ \\
\hline \multirow[t]{4}{*}{ Parents } & Age & $38.54 \pm 4.22$ \\
\hline & Religion (yes/no) & $9(34.6) / 17(65.4)$ \\
\hline & Marriage (yes/no) & $24(92.3) / 2(7.7)$ \\
\hline & Educational level (high school/university) & $11(42.3) / 15(57.7)$ \\
\hline
\end{tabular}


CY 체크리스트는 Cronbach- $\alpha=0.75-0.95$ 로 높은 신뢰도를 보였다.

\section{2) 부모의 삶의 질 평가도구(WHOQOL-BREF)}

보호자의 삶의 질 측정을 위해서는 WHO가 제시한 WHOQOL-100 을 축약하여 총 26 문항으로 구성된 간편형 WHOQOL-BREF를 사용 하였다. 본 설문지는 전반적인 삶의 질 영역(2문항), 신체적인 영역(7문 항), 심리적인 영역(5문항), 사회적인 영역(3문항), 생활환경영역(8문 항)으로써 총 26 문항으로 구성되고, 모든 영역은 Likert 5 점 척도로 구성되어 있다. 각 문항의 응답은 매우 나쁨(1점), 나쁨(2점), 그저 그 렇다(3점), 좋음(4점), 매우 좋음(5점)으로 분류된다. 부정적 질문인 3 번, 4번, 26번은 매우 나쁨(5점), 나쁨(4점), 그저 그렇다(3점), 좋음(1 점), 매우 좋음(1점)으로 분류된다. WHOQOL-BREF는 Cronbach$\alpha=0.75-0.85$ 로 나타났다. ${ }^{14}$

\section{3) 대근육 운동기능 분류체계(GMFCS)}

Palisano 등 ${ }^{19}$ 에 의해 개발된 GMFCS는 뇌성마비 아동을 각 연령대 (1-2세 미만, 2-4세 미만, 4-6세 미만, 6-12세 미만)별로 나누어 장애 정 도를 5단계로 분류하였다. 운동에 기능적 제한이 있는지, 보행 시 보 조기구나 휠체어가 필요한지에 따라서 운동 기능의 단계를 분류한 다. GMFCS는 아동이 얼만큼 할 수 있는지에 중점을 두어 판단을 한 다. GMFCS 1 단계는 경함, 2,3 단계는 중등도, 4,5 단계는 중증으로 분 류하였다. ${ }^{20} \mathrm{GMFCS}$ 는 $\mathrm{r}=0.91$ 의 신뢰도를 보였다.

\section{3. 연구절차}

본 설문지는 2017년 5-8월까지 개별 봉투에 넣은 후 소아 물리치료 전 문 기관으로 보내어 연구 선정기준에 적합한 아동의 보호자를 대상 으로 하였다. 설문지 응답 시간은 약 20-30분 정도 소요되었다. ICF$\mathrm{CY}$ 체크리스트는 보호자와 치료사가 작성하였으며, WHOQOL-
$\mathrm{BREF}$ 는 보호자가, GMFCS는 객관성을 부여하기 위해 2년차 이상의 소아물리치료사가작성하였다. 총 55 부를 배부하여 32 부가 회수되었 고, 23 부가 회수되지 않았다. 이 중 오류가 있는 6 부를 제외하고 총 26 부의 자료를 사용하여 분석하였다.

\section{4. 분석 방법}

본 연구에서 수집된자료는 SPSS ver. 20.0 (SPSS Inc. Chicago, IL, US)을 이용하여 통계 처리하였다. 아동과 보호자의 일반적인 특성은 빈도 분석을 사용하였다. ICF-CY체크리스트가 삶의 질에 미치는 영향을 알아보기 위해 다중회귀분석(multiple regression analysis)을 실시하였 고, GMFCS와 보호자의 삶의 질의 상관관계를 보기 위해 상관분석 (correlation analysis)을 실시하였다. 통계적 검증을 위한 유의수준은 0.05 로 설정하였다.

\section{결 과}

\section{1. 연구 대상자의 특성}

아동과 보호자의 일반적인 특성은 다음과 같다(Table 1).

\section{ICF-CY의 기능영역이 보호자의 삶의 질에 미치는 영향}

ICF-CY 기능영역의 세부적인 요소가 보호자의 삶의 질에 미치는 영 향에 대해 보면, 종속변수인 뇌성마비 아동 보호자의 삶의 질에 대하 여 다중회귀분석 설명력(R2)은 총 분산의 $68.4 \%$, 유의확률 0.002 로 통 계적으로 유의한 것으로 나타났다. 보호자의 삶의 질에 영향을 미치 는 독립변수로는 신경근육골격 및 운동과 관련된 기능(b7)이 유의하 게 나타났다 $(\mathrm{p}<0.05)($ Table 2).

Table 2. Effect of ICF-CY functional level on the quality of life of cerebral palsy parents

\begin{tabular}{|c|c|c|c|c|c|c|}
\hline \multirow{2}{*}{ Dependent variable } & \multirow{2}{*}{ Independent variables } & \multicolumn{2}{|c|}{ Unstandardized coefficients } & \multicolumn{3}{|c|}{ Standardized coefficients } \\
\hline & & $\beta$ & Std.Err & $\beta$ & $\mathrm{t}$ & $\mathrm{p}$ \\
\hline \multirow[t]{8}{*}{ Quality of Life } & Number & 94.392 & 3.004 & & 31.424 & $0.000^{* * *}$ \\
\hline & b1 & -0.290 & 1.576 & -0.033 & -0.184 & 0.856 \\
\hline & b2 & -2.495 & 1.728 & -0.225 & -1.444 & 0.166 \\
\hline & b3 & -0.673 & 1.384 & -0.108 & -0.487 & 0.632 \\
\hline & b4 & -3.528 & 4.304 & -0.124 & -0.820 & 0.423 \\
\hline & b5 & -2.531 & 2.461 & -0.245 & -1.029 & 0.317 \\
\hline & b6 & 2.225 & 2.292 & 0.160 & 0.971 & 0.344 \\
\hline & b7 & -4.334 & 1.378 & -0.522 & -3.146 & $0.006^{* *}$ \\
\hline
\end{tabular}

${ }^{* *} \mathrm{p}<0.01$.

Adjusted R square $=0.562, F=5.577$

b1, mental functions; b2, sensory functions and pain; b3, voice and speech functions; b4, functions of the cardiovascular, haematological, immunological and respiratory system; b5, functions of the digestive, metabolic and endocrine systems; b6, genitourinary and reproductive functions; b7, neuromusculoskeletal and movement-related functions. 
Table 3. Effect of ICF-CY activities, participation on the quality of life of cerebral palsy parents

\begin{tabular}{|c|c|c|c|c|c|c|}
\hline \multirow{2}{*}{ Dependent variable } & \multirow{2}{*}{ Independent variables } & \multicolumn{2}{|c|}{ Unstandardized coefficients } & \multicolumn{3}{|c|}{ Standardized coefficients } \\
\hline & & $\beta$ & Std.Err & $\beta$ & $\mathrm{t}$ & $p$ \\
\hline \multirow[t]{10}{*}{ Quality of Life } & Number & 90.975 & 3.795 & & 23.975 & $0.000^{* * *}$ \\
\hline & d1 & 3.471 & 3.289 & 0.532 & 1.055 & 0.307 \\
\hline & $\mathrm{d} 2$ & -4.421 & 2.909 & -0.651 & -1.520 & 0.148 \\
\hline & d3 & -5.481 & 3.165 & -0.885 & -1.732 & 0.103 \\
\hline & $\mathrm{d} 4$ & -4.836 & 2.367 & -0.634 & -2.043 & 0.058 \\
\hline & d5 & -3.644 & 3.771 & -0.584 & -0.966 & 0.348 \\
\hline & d6 & 3.838 & 3.058 & 0.609 & 1.255 & 0.227 \\
\hline & d7 & -1.257 & 1.643 & -0.129 & -0.765 & 0.455 \\
\hline & d8 & 3.934 & 5.813 & 0.422 & 0.677 & 0.508 \\
\hline & d9 & 3.406 & 3.605 & 0.395 & 0.945 & 0.359 \\
\hline
\end{tabular}

Adjusted R square $=0.499, \mathrm{~F}=3.771$

d1, learning and applying knowledge; d2, general task and demands; d3, communication; d4, mobility; d5, self-care; d6, domestic life; d7, interpersonal interactions and relationships; d8, major life areas; d9, community, social and civic life.

Table 4. Effect of ICF-CY environmental factors on the quality of life of cerebral palsy parents

\begin{tabular}{|c|c|c|c|c|c|c|}
\hline \multirow{2}{*}{ Dependent variable } & \multirow{2}{*}{ Independent variables } & \multicolumn{2}{|c|}{ Unstandardized coefficients } & \multicolumn{3}{|c|}{ Standardized coefficients } \\
\hline & & $\beta$ & Std.Err & $\beta$ & $\mathrm{t}$ & $p$ \\
\hline \multirow[t]{6}{*}{ Quality of Life } & Number & 84.915 & 2.063 & & 41.163 & $0.000^{* * *}$ \\
\hline & e1 & -4.382 & 2.884 & -0.400 & -1.519 & 0.144 \\
\hline & e2 & -4.972 & 2.626 & -0.316 & -1.894 & 0.073 \\
\hline & e3 & -6.930 & 3.343 & -0.676 & -2.073 & 0.051 \\
\hline & e4 & 3.148 & 3.342 & 0.276 & 0.942 & 0.357 \\
\hline & e5 & 8.342 & 3.332 & 0.570 & 2.504 & $0.021^{*}$ \\
\hline
\end{tabular}

Adjusted R square $=0.478 \mathrm{~F}=3.545$

e1, products and technology; e2, natural environment and human-made changes to environment; e3, support and relationships; e4, attitudes; e5, services, systems and policies.

${ }^{*} \mathrm{p}<0.05$.

\section{ICF-CY의 활동과 참여 영역의 수행이 보호자의 삶의 질에 미치는 영향}

ICF-CY 활동과 참여영역의 수행에서 보호자의 삶의 질에 미치는 영 향에 대해 보면, 종속변수인 뇌성마비 아동 보호자의 삶의 질에 대하 여 다중회귀분석 설명력(R2)은 총 분산의 $68 \%$, 유의수준은 0.01 로 통 계적으로 유의한 것으로 나타났다. 통계적으로 유의하게 나타났지만 보호자의 삶의 질에 영향을 주는 세부적인 요소는 통계적으로 유의 하게 나타나지 않았다 $(\mathrm{p}>0.05)$ (Table 3$)$.

\section{ICF-CY 환경영역이 보호자의 삶의 질에 미치는 영향}

ICF-CY 환경영역에서 보호자의 삶의 질에 미치는 영향에 대해 보면, 종속변수인 뇌성마비 아동 보호자의 삶의 질에 대하여 다중회귀분석 설명력(R2)은 총 분산의 $46.2 \%$, 유의수준 0.021 로 통계적으로 유의한 것으로 나타났다. 보호자의 삶의 질에 영향을 미치는 독립변수로는 서 비스, 시스템 그리고 정책(e5)이 유의하게 나타났다 $(\mathrm{p}<0.05)$ (Table 4).

\section{5. 아동의 GMFCS level과 보호자의 삶의 질 간의 상관관계}

아동의 GMFCS와 보호자의 삶의 질 간의 상관관계를 살펴보면, 유 의확률 $0.001, \mathrm{r}=-0.612$ 로 음의 상관관계를 보였다 $(\mathrm{p}<0.001)$.

\section{고 찰}

본 연구는 ICF-CY의 세부적인 요소인 뇌성마비 아동의 기능, 활동과 참여, 환경요인과 아동의 GMFCS 단계가 뇌성마비 아동을 보육하는 보호자의 삶의 질에 영향을 미치는지 알아보는 것이 목적이었다. 본 연구의 결과에서 ICF-CY의 요소들에서 기능, 활동과 참여, 환경요인 이 삶의 질에 영향을 미치는 것을 확인할 수 있었다. 하지만, 각 ICF$\mathrm{CY}$ 의 요소 중 일부분에서만 유의한 관련성이 나타났다. 뇌성마비 아 동을 보육하는 보호자의 삶의 질과 유의한 관련성이 있는 ICF-CY세 부적인 요인으로서 기능영역에 포함되어 있는 신경근육골격 및 운동 과 연관된 기능(b7)과 환경요인영역에서 서비스와 시스템 및 정책(e5) 이 유의한 관련성이 있었다.

본 연구에서는 ICF-CY의 기능영역에 포함되어 있는 세부적인 요인 
으로써 신경근육골격 및 운동과 연관된 기능의(b7) 점수가 높을수 록 뇌성마비 아동을 보육하는 보호자의 삶의 질에 대한 만족도가 높 아짐을 알 수 있었다. Jo 등ㄹㅇㅢ 연구에서 학령기 뇌성마비 아동을 대 상으로 GMFCS 분류를 기초로 하여 뇌성마비 아동의 삶의 질을 확 인한 연구에서 독립적인 계단 오르기가 가능한 뇌성마비 아동과 같 이 기능적인 수준이 높을수록 삶의 질에 대한 만족도가 높아진다고 보고하였으며, Lee 등릐 의 연구에서도 manual ability classification system (MACS)을 토대로 하여 기능수준이 높을수록 삶의 질이 유의하 게 높아진다고 하였다. 신경근육골격 및 운동과 연관된 기능과 삶의 질에서는 유의한 관련성이 있다는 것은 선행 연구에서도 유사하게 나타났으며, 이는 우리 연구 결과를 뒷받침하고 있다. 비록 선행연구 들은 뇌성마비 아동의 기능 정도와 아동의 삶의 질에 대한 연구였으 며, 본 연구에서는 보호자를 대상으로 하여 조사한 연구로써 만족도 평가의 대상자에 대한 차이는 존재한다. 하지만, 심리적 스트레스에 대한 연구를 토대로 유추해 보면, Lee ${ }^{23}$ 의 연구에서 아동의 장애가 심 할수록 뇌성마비 아동을 보육하는 보호자의 스트레스 지수가 높아 진다고 보고하였으며, 이는 기능적 움직임의 수준이 높을수록 보호 자의 스트레스는 감소될 수 있음을 고려해볼 수 있을 것이다. 또한 뇌 성마비 아동의 장애의 정도를 포괄적으로 점수화하여 보호자 삶에 만족도와 비교한 연구에서도 장애 정도가 심할수록 보호자의 심리 적 웰빙이 낮아진다고 보고하였다. ${ }^{24}$ 이전 선행 연구들에서 기능영역 의 세부적인 요인들에서 비뇨생식기능과 생식기능, 감각기능과 통증, 정신기능에서 뇌성마비 아동의 삶의 질과는 유의한 관련이 있다고 보고하였다. 하지만, 본 연구의 결과에서는 선행연구와는 달리 유의 한 차이가 보이지 않았다. 우리의 연구와 선행연구와의 결과 차이는 선행연구에서 뇌성마비 아동을 대상으로 삶의 질을 평가하여 나타 난 결과라 사료되며, 우리의 연구 결과는 뇌성마비를 보육하는 보호 자의 삶의 질을 조사하여 차이가 나타난 것으로 생각된다.

환경요인영역에서는 서비스와 시스템 및 정책(e5)에 대한 점수가 높을수록 뇌성마비 아동을 보육하는 보호자의 삶의 질에 대한 만족 도가 높아짐을 알 수 있었다. 뇌성마비를 가진 보호자들은 아동의 치 료, 교육 등으로 인해 재정적 어려움을 겪을 수 있으며, 이는 뇌성마비 를 담당하는 보호자에게 스트레스를 가중시킬 수 있다. 반면, 경제적 인 어려움에 처했을 때 사회적 지원은 심리적 안정감을 가져올 수 있 다고 하였다. ${ }^{25}$ 따라서, 뇌성마비 아동의 보호자들이 아동의 장애로 인하여 발생하는 심리적 어려움을 경감시키는 데 뇌성마비 아동에 대한 서비스와 시스템 및 정책이 중요한 역할을 한다고 생각될 수 있 다. $\mathrm{Choi}^{26}$ 의 연구에서 사회적 지지는 환자들의 자립생활에 유의한 상관관계가 있으며, 이는 사회 정책적인 지원 및 지지는 환자들의 삶 의 만족도를 증가시킬 수 있는 요인으로 작용할 수 있다고 해석할 수 있다. 하지만, 다른 4 개 영역에서는 유의한 관련성을 찾을 수 없었으
며, 이는 뇌성마비를 보육하는 보호자의 관심이 아동의 기능과 사회 정책적 지원에 대해 더 많이 우선 순위를 가짐으로써 나타난 결과라 생각되어진다.

우리의 연구 결과에서 활동과 참여 영역에서 모두 유의한 관계가 나타나지 않았다. 이전 선행연구들에서 뇌성마비 아동의 이동, 활동, 사회인지 등에서 신체적 삶의 질과 유의한 상관관계가 있다고 보고 하였다. ${ }^{10,27,28}$ 하지만 본 연구에서는 선행연구들과 다르게 활동과 참 여영역에서 유의한 차이가 없었다. 본 연구에서 선행 연구들과 다르 게 유의한 차이가 나타나지 않은 이유는 아동의 나이가 어리고, GMFCS 1,2 단계인 아동들이 20명 이상으로 아동을 이동시키는 데 보호 자가 보조에 대한 어려움을 상대적으로 덜 느끼기 때문이라고 생각 된다. Beckung 등 29 는 GMFCS와 bimanual fine motor function (BFMF) 의 1,2 단계가 참여에 대한 부분들이 높아지기 때문이라고 보고하였 다. 또한, 학령기 뇌성마비 아동에서 3 단계 아동이 4,5 단계 아동보다 삶의 질이 높게 나타났고, 장애 정도에 따라 차이가 있다고 보고하였 다. ${ }^{30}$ 추가적으로 본 연구에서는 일반학교에 다니는 아동이 17 명으로 일반아동들과 공동체 생활을 경험하고, 스스로 하려는 횟수가 많아 져 보호자가 해줄 부분이 이전보다 적어진 부분이라고 생각된다. $\mathrm{Lee}^{23}$ 는 정상발달 아동들과의 학교 생활이 뇌성마비 아동의 활동성 을 자극하여 보다 증진시킬 수 있다고 보고하였다.

선행연구들은 뇌성마비 아동의 삶의 만족도에 대한 연구나 뇌성 마비 아동의 장애의 정도를 포괄적으로 점수화하여 보호자 삶에 만 족도와 비교한 연구들이 대부분이었으며, 17,28 뇌성마비 아동을 대상 으로 한 ICF-CY의 세부적인 요인들과 장애아동을 보육하는 보호자 에 삶의 질에 관한 연구는 이루어지지 않았다. ${ }^{25}$ 따라서, 우리의 연구 는 ICF-CY를 바탕으로 뇌성마비 아동 장애와 보호자의 삶의 질에 관 계를 해석하는 데 기초가 될 수 있는 연구라 생각된다. 본 연구는 향 후 보완되어야 할 몇가지 제한점을 가지고 있다. 첫째, 자료 수집에 있 어서 많은 연구대상자를 포함시키는 것이 어려웠다. 상대적으로 대 상자 수가 적기 때문에 연구의 결과를 전체 뇌성마비 아동 보호자의 삶의 질에 적용하여 일반화하기에는 어렵다. 둘째, 뇌성마비 아동의 교육방법, 뇌성마비형태 등 아동의 특성에 따른 보호자의 삶의 질을 보지 못하였다. 셋째, 설문지를 주로 아동을 돌보는 어머니가 작성하 였기 때문에 보호자의 삶의 질을 아버지의 삶의 질로 봐서는 안 된다. 앞으로 본 연구의 제한점을 보완한 연구들이 지속적으로 이루어져 야할 것이다.

\section{REFERENCES}

1. Bax M, Goldstein M, Rosenbaum PL et al. Proposed definition and classification of cerebral palsy. Dev Med Child Neurol. 2005;47:571-6. 
2. Dalvand H, Dehghan L, Feizy A et al. Effect of the Bobath technique, conductive education and education to parents in activities of daily living in children with cerebral palsy in Iran. HongKong J Occup Ther. 2009;19:14-9.

3. Cans C. Prevalance and characteristics of children with cerebral palsy in Europe. Dev Med Child Neurol. 2002;44(9):633-40.

4. Jette AM. Toward a common language for function, disability, and health. Phys Ther. 2006;86(5):726-34.

5. Ministry of Health and Welfare. International classification of functioning, disability, and health(ICF). 2004.

6. WHO. International classification of functioning, disability and health: ICF. Geneva, World Health Organization, 2001.

7. Statistics Korea. WHO-FIC meeting business trip report. 2008.

8. Davis E, Waters E, Mackinnon A. Pediatric quality of life instrument: a review of the impact of the conceptual framework on outcomes. Dev Med Child Neurol. 2006;48:311-8.

9. Boyle CA, McGee H, Hickey A et al. Individual quality of life in patients undergoing hip replacement. The Lacet. 1992;339:1088-91.

10. Lee BH, KO JY. Influential factors for health related quality of life in children with mental retardation and cerebral palsy. The Korean Society of Special Education. 2010;22:105-26.

11. Yoo HK. A literature review on the important factors related to the quality of life in families with disabled children. Journal of Special Education \& Rehabilitation Science. 2007;46(4):19-54.

12. Lee HJ, Eo YS. A study on family functioning and burden of parents with cerebral palsy children. Korean J Child Health Nurs. 2000;6(2):199-211.

13. Kim DH. A study on the health state and burden of the chronic patient's family members. Pusan National University. Dissertation of Master's Degree. 1998.

14. Kwon MJ. Satisfaction of utilization of physical therapy and quality of life for caregivers of cerebral palsy children. J Kor Phys Ther. 2009:55-63.

15. Shelly A, Davis E, Waters E et al. The relationship between quality of life and functioning for children with cerebral palsy. Dev Med child Neurol, 2008;50(3):199-203.

16. Mohammed FMS, Ali SM, Mustafa MAA. Quality of life of cerebral palsy patients and their caregivers: a cross sectional study in a rehabilitation center Khartoum-Sudan. J Neurosci Rural Pract. 2016;7(3):355-61.

17. Moon SW. Studies on the quality of life of children with cerebral palsy using the ICF-CY. Sehan University. Dissertation of Master's Degree. 2014.

18. Park JK, Kim JH. Basic research of utilizing ICF-CY for the development of the IEP for students with disabilities. Korean Council of Physical, Multiple, \& Health Disabilities. 2012;55(3):47-70.

19. Palisano RJ, Rosenbaum PL, Russell DJ et al. Development and reliability of a system to classify gross motor function in children with cerebral palsy. Dev Med Child Neurol. 1997;39(4):214-23.

20. FawkeJ. Neurological outcomes following preterm birth. Semin Fetal Neonatal Med. 2007;12:374-82.

21. Jo SM, Oh DW, Kim SY et al. A study of the quality of life and participation in everyday activities for school aged children with cerebral palsy. J Korean Soc Occup Ther. 2010;18(2):95-106.

22. Lee JW. A study of the functions, activities and participation and quality of life in school -aged children with cerebral palsy. Sahmyook University. Dissertation of Master's Degree. 2013.

23. Lee MJ. Studies on the correlation between the severity of cerebral malaise and mother's stress. Chung-ang University. Dissertation of Master's Degree. 1991.

24. Kim SY, Oh HK. Well-being of mothers of children with disabilities. KSRPD. 2010;14(1):139-58.

25. Holahan CJ, Moos RH. Personality, coping and family resourses in stress reistance a longitudinal analysis. J Pers Soc Psychol. 1986;51(2):389-95.

26. Choi SW. A study on factors that affect independence living of people with cerebral palsy. Hanil University. Dissertation of Master's Degree. 2005.

27. Love S. Better description of spastic cerebral palsy for reliable classification. Dev Med Child Neurol. 2007;49:24-5.

28. Arnaud C, White-Koning M, Michelsen SI et al. Parent-reported quality of life of children with cerebral palsy in Europe. Pediatrics. 2008;121(1):5464.

29. Beckung E, Carlsson G, Carlsdotter S et al. The natural history of gross motor development in children with cerebral palsy aged 1 to 15 years. Dev Med Child Neurol. 2007;49(10):751-6.

30. Lee BH, Song CH, Kim NJ et al. A study of the health related quality of life in school-aged children with severe cerebral palsy. Journal of Coaching Development. 2007;9(1):207-17. 